\title{
Utilização de Resíduos de Borra de Café e Serragem na Moldagem de Briquetes e Avaliação de Propriedades
}

\author{
Use of Waste Coffee Grounds and Sawdust in \\ Briquettes Molding and Evaluation of Properties
}

\author{
Larissa de Souza Soares ${ }^{1}$, Virgínia Aparecida da Silva Moris ${ }^{1}$, \\ Fábio Minoru Yamaji ${ }^{2,3}$, Jane Maria Faulstich de Paiva ${ }^{1,3}$
}

\footnotetext{
${ }^{1}$ Dep. de Eng. de Produção, UFSCar/Campus Sorocaba, Rod. João Leme Santos, Km 110 - 18052-780, Sorocaba, SP

2 Dep. de Ciências Ambientais, UFSCar/Campus Sorocaba, Rod. João Leme Santos, Km 110 - 18052-780, Sorocaba, SP

${ }^{3}$ Pós-graduação em Ciência dos Materiais - PPGCM, UFSCar/Campus Sorocaba, Rod. João Leme Santos, Km 110 18052-780, Sorocaba, SP

e-mail: laarissa.soares@hotmail.com,vimoris@ufscar.br,fmyamaji@ufscar.br, jane@ufscar.br
}

\begin{abstract}
RESUMO
Este trabalho envolveu a moldagem de briquetes com utilização de resíduos de pó borra de café e serragem de madeira de eucalipto. Os briquetes produzidos a partir de biomassa vegetal podem ser aplicados como substituintes de outros combustíveis utilizados em caldeiras de processos industriais ou até mesmo para aquecimento de residências, em regiões frias, com utilização de equipamentos mais simples. No Brasil e em muitos países uma grande quantidade de resíduos de borra de café é produzida e desperdiçada no cotidiano e em indústrias de café solúvel. A serragem de madeira também é um resíduo bastante comum no Brasil, principalmente, em algumas cidades que concentram grande número de empresas que processam madeira. Assim, a moldagem de briquetes com estes resíduos sólidos é uma oportunidade de reaproveitar os resíduos para produzir um tipo de combustível proveniente de fonte renovável, contemplando também aspectos relacionados à bioenergia e Produção Mais Limpa $(\mathrm{P}+\mathrm{L})$. Desta forma, no presente trabalho foram realizadas moldagens de briquetes utilizando o pó da borra de café e serragem de madeira em diferentes proporções destes materiais para avaliar propriedades mecânicas de compressão diametral. Também foram realizadas análises para determinar os teores de umidade, voláteis e cinzas, além da determinação do poder calorífico superior (PCS). Todas as composições de briquetes contendo serragem ocasionaram acréscimos nos valores das médias das propriedades de resistência máxima à compressão diametral e módulo de elasticidade, quando comparados aos valores destas propriedades dos briquetes moldados apenas com a borra de café. As diferentes composições de briquetes contendo serragem apresentaram valores próximos de resistência à compressão diametral. Considerando os valores do poder calorífico (PCS), todas as amostras apresentaram resultados semelhantes em comparação com a literatura. Os briquetes contendo somente borra de café na composição apresentaram resultados de teores de cinzas, voláteis e PCS similares aos das amostras contendo serragem. Porém, os briquetes contendo somente borra de café apresentaram valores inferiores de resistência máxima à compressão quando comparados a todos os outros briquetes moldados também com serragem.
\end{abstract}

Palavras-chave: resíduo, café, serragem de madeira, briquete.

\section{ABSTRACT}

This work involved the molding briquettes with use of powder of coffee and eucalyptus wood sawdust residues. The briquettes produced from biomass can be applied as replacements for other fuels used in boilers for industrial processes or even for heating home in cold regions, using simple equipment. In Brazil and in many countries a large amount of waste coffee grounds is produced and wasted in daily life and in soluble coffee industry. The wood sawdust is also a fairly common residue in Brazil, especially in some cities that concentrate large number of companies that process wood. Then the molding of briquettes with these solid wastes is 
an opportunity to reuse the waste to produce a type of fuel from renewable sources, also including aspects related to bioenergy and Cleaner Production. Thus, in the present study were molded briquettes using the powder of coffee grounds and wood sawdust in different proportions of these materials to evaluate mechanical properties of diametrical compression. Also analyzes were performed to determine the moisture, volatile matter and ash contents, besides the determination of the calorific value content (PCS). All compositions containing sawdust briquettes caused increases in mean values of maximum resistance properties diametrical compression and elastic modulus when compared to the values of these properties of briquettes molded only with the coffee grounds. The different composition of briquettes containing sawdust presented similar value of resistance to diametrical compression. Considering the calorific values (PCS), all samples showed similar results compared to the literature. The briquettes containing only coffee grounds in the composition presents results of ash, volatile contents and PCS similar to the samples containing sawdust. However, the briquettes containing only coffee grounds showed lower maximum compressive strength compared to all other also molded with sawdust briquettes.

Keywords: residue, coffee, wood sawdust, briquette.

\section{INTRODUÇÃO}

Alguns materiais provenientes de fontes renováveis como os resíduos vegetais estão se tornando uma alternativa promissora para a geração da denominada bioenergia, em substituição pelo menos parcial de combustíveis de origem fóssil e não renovável. [1]

O uso de combustíveis não-renováveis como carvão mineral, petróleo entre outros também tem se tornado uma grande preocupação ambiental devido ao fato de serem potencialmente poluentes e, em alguns casos, de maior custo [1, $\underline{2}]$.

A utilização de alternativas para a produção de energia também auxilia a economia e o reaproveitamento de resíduos de produção agrícola e/ou agroindustriais, como palha de milho, sabugo de milho, casca de arroz, casca de café, bagaço de cana-de-açúcar, casca de soja entre outros resíduos ou subprodutos que possam vir a ser utilizados como matéria-prima para biocombustíveis ou bioenergia $[\underline{3}, \underline{4}, \underline{5}, \underline{6}]$.

Nesse contexto, a busca por fontes alternativas de energia tem sido um desafio constante, que aponta na direção da compactação de biomassa na forma de briquete como uma promissora opção [7]. No Brasil, por exemplo, são produzidos por ano cerca de 330 toneladas de resíduos de biomassa que muitas vezes não são aproveitados como fonte de energia devido a inadequadas características como baixa densidade, baixo valor de poder calorífico, alto teor de umidade, que ocasionam altos custos durante o transporte e estocagem. Algumas destas características podem ser alteradas com a secagem e posterior compactação dos resíduos de biomassa na forma de briquete [].

Os briquetes são constituídos de materiais sólidos, geralmente, na forma de pequenas partículas ou pó que são prensados em equipamentos hidráulicos ou prensas mecânicas com o intuito de se obter um material compactado, geralmente, na forma de pequenos cilindros ou discos, para serem utilizados como combustíveis [9].

A moldagem de briquetes também é denominada briquetagem e entre suas vantagens são destacadas a diminuição no volume físico do material devido à compactação, alto valor de capacidade calorífica por volume, facilidades de transporte, manuseio, estocagem e redução de área para estoque [ㄱ, 10].

Dentre os diversos materiais que podem ser utilizados para a briquetagem alguns resíduos lignocelulósicos como pó de serragem de madeira, casca de arroz, bagaço de cana, etc, tem se mostrado superiores à lenha quanto ao seu poder calorífico [11].

Em relação ao formato e às condições do ensaio mecânico, os briquetes cilíndricos são considerados mais adequados do que briquetes em outro formato, além da maneira como são condicionados à compressão - em sua superfície - aumentar sua resistência mecânica em cerca de 10 vezes [12].

O resíduo de borra de café usado neste trabalho é justificado, entre outras razões, pela fácil disponibilidade no Brasil e pela possibilidade de estudar outras vantagens, como o óleo presente no resíduo [1]]. O re- 
síduo de café do tipo borra em pó é composto em sua maioria por matéria orgânica (aproximadamente 91\%) e constitui um resíduo sólido rico em lipídios [14].

Essa última característica é fundamental para que o processo de briquetagem ocorra com sucesso, o que eleva o potencial da borra de café em apresentar ótimos resultados, embora esse teor de óleo varie conforme o tipo de café usado. Geralmente, a borra de café apresenta em torno de 20\% de óleo [15].

No processo industrial de fabricação de café solúvel é gerada uma quantidade considerável de borra (para cada tonelada de café é obtida aproximadamente $480 \mathrm{~kg}$ de borra), que é considerado como resíduo sólido e pode ser utilizado para gerar energia nas caldeiras industriais [15].

Neste caso, nas indústrias de café solúvel torna-se necessário realizar algumas adaptações nas caldeiras, para que haja combustão de forma eficiente e sem gerar materiais poluentes [16]. Para ser utilizada nas caldeiras das indústrias de café, a borra precisa passar por um processo de secagem, o qual pode ser realizado por secadores do tipo rotativo, leito fluidizado ou pneumático, incluindo uma etapa de eliminação prévia de água, por exemplo, por prensagem ou peneira vibratória. A secagem, neste caso, geralmente é necessária, pois a borra úmida pode gerar uma grande quantidade de vapor, o que implica em maiores custos operacionais, necessidade de complemento de combustível, e maior tamanho da câmara de secagem, devido ao volume de vapor produzido, pois a umidade reduz o poder calorífico da borra [16].

Os países produtores de café buscam cada vez mais inovações na forma de reciclar os resíduos obtidos em sua produção, por razões não somente ecológicas como também financeiras. Exemplos dessas inovações são: a elaboração de processos de compostagem, produção de fertilizantes orgânicos, biogás, entre outros, além da utilização na geração de energia para a produção do próprio café solúvel [16].

No processo de escolha das melhores condições dos resíduos de café a serem utilizados deve-se levar em conta alguns critérios como, por exemplo, a granulometria adequada. PEREIRA et al. [17] observaram que durante o processo de peneiramento de alguns materiais, a probabilidade de o material retido nas peneiras de menor abertura - grãos muito finos - conter determinadas impurezas é maior, podendo não se adequar conforme a situação em que o material será utilizado.

No caso do pó da borra de café, alguns outros fatores como a temperatura da produção dos briquetes e a secagem do material também devem ser observados, já que este último possui influência sobre a liberação do óleo pela borra de café. Para que essa liberação também ocorra com máxima eficiência, deve-se garantir que a borra de café seja mantida em temperatura e condições de umidade adequadas, de forma a não haver perda de suas propriedades [18].

Os briquetes de modo geral também possuem algumas formas de serem avaliados. BALLARIN E NOGUEIRA [19] observaram a importância de se estabelecer padrões que delimitem as melhores e piores condições de uso dos mesmos. Isso pode ser feito, por exemplo, através da análise do Módulo de Elasticidade (MoE), sendo que quanto maior esse valor, geralmente, maior será a resistência mecânica do briquete obtido, que é uma propriedade importante para transporte do briquete, principalmente, no caso de exportação.

Com todas suas características e propriedades, o briquete produzido a partir de biomassa vegetal certamente é uma fonte de energia, que pode ser obtida com pouca tecnologia e investimentos geralmente baixos [11, 20, 21]. Outro fator favorável é apontado por ROY e CORSCADDEN [22] como uma das razões para atribuir ao briquete moldado com biomassa o título de menos poluente, pois sua queima tende a gerar uma quantidade menor de gases poluentes na atmosfera.

Além do exposto, o Brasil é um dos maiores produtores de café do Mundo. No período compreendido entre os meses de novembro/2011 e outubro/2012, a Associação Brasileira da Indústria de Café (ABIC) registrou o consumo de 20,33 milhões de sacas pela população, o que representa um acréscimo de 3,09\% em relação ao período anterior correspondente (nov/10 a out/11), que foi de 19,72 milhões de sacas. Esse resultado mostra que o Brasil ampliou seu consumo interno de café em 610 mil sacas nos 12 meses considerados [23].

Portanto, a grande produção e consumo de café levam a geração de uma enorme quantidade de resíduos de pó de borra de café no Brasil; além dos resíduos do cultivo da planta, como o pergaminho (endocarpo) de café que também podem ser utilizados para briquetagem [4]. 
A serragem de madeira também é amplamente disponível no Brasil, principalmente, em algumas regiões e cidades do interior do estado de São Paulo [8] que possui muitas empresas de pequeno, médio e grande porte que processam madeira para fabricação de móveis e outras utilidades. O uso da serragem de madeira de eucalipto para compor as composições de briquetes, neste trabalho, está relacionado ao potencial para briquetagem deste resíduo [24, 25].

Todas essas vantagens, aliadas à grande quantidade de biomassa de fácil obtenção e com composição química favorável ao processo de queima, tornam a briquetagem de resíduos, como a borra de café e a serragem de madeira, uma boa alternativa para a geração da denominada bioenergia para as indústrias, comércio ou residências.

Desta forma, este trabalho foi desenvolvido em duas etapas principais, moldagem de briquetes utilizando somente o pó da borra de café e, posteriormente, a briquetagem de composições utilizando misturas de pó de borra de café e serragem de madeira de eucalipto.

\section{MATERIAIS E MÉTODOS}

\subsection{Borra de café e Serragem de Madeira}

Neste trabalho foram utilizados resíduos de pó de borra de café coletados na Universidade Federal de São Carlos - Campus Sorocaba, a partir de duas fontes principais: máquina de café automática, que processa grãos de café; e resíduos de pós de café comerciais, que ficam retidos em filtros de papel.

Após a coleta os resíduos de borra de café, provenientes das duas fontes citadas, foram misturados com auxílio de espátula e levados ao Laboratório de Processos Industriais para os procedimentos de secagem.

A serragem de madeira de eucalipto utilizada foi obtida de empresas de pequeno e médio porte localizadas na cidade de Sorocaba-SP.

Os processos de secagem da borra de café e da serragem foram realizados, separadamente, com utilização de uma estufa circulação de ar (marca Marconi, modelo MA035/1), por um período de 24 horas, a $90^{\circ} \mathrm{C}$. Após a secagem, o material foi retirado da estufa e acondicionado em embalagens plásticas para posterior classificação granulométrica para a moldagem dos briquetes.

\subsection{Classificação granulométrica da borra de café e serragem}

A classificação granulométrica da borra de café, previamente seca na estufa, foi realizada com auxílio de uma sequência de peneiras com diferentes aberturas acopladas no equipamento agitador orbital de peneiras com batidas intermitentes (marca Marconi, modelo MA750) localizado no Laboratório de Processos Industriais do Campus Sorocaba. A sequência de peneiras utilizada foi de 9-14-20-35-60-100 Mesh, de acordo com testes preliminares.

Dentre as peneiras selecionadas para realizar a análise da distribuição granulométrica foi observada uma maior quantidade de material retido nas peneiras de 35 Mesh e 60 Mesh. As Figuras 1 e 2 ilustram os briquetes moldados com as duas distribuições granulométricas: material passante na malha com granulometria 20 Mesh e retido na malha com granulometria 35 Mesh e também o material passante na malha com granulometria 35 Mesh e retido na malha com granulometria 60 Mesh. A quantidade do material passante pela malha com granulometria 20 Mesh e retido na malha com granulometria 35 Mesh apresentou quantidade superior de massa retida comparada a demais peneiras e por esse motivo foi a granulometria escolhida e utilizada nos ensaios para a moldagem dos briquetes da mistura de borra de café e serragem em diferentes proporções. A distribuição granulométrica da serragem de madeira utilizada na moldagem dos briquetes foi o material passante na malha com granulometria 20 Mesh e retido na malha com granulometria 35 Mesh, conforme detalhado a seguir.

\subsection{Moldagem dos briquetes com borra de café e serragem}

O resíduo de pó peneirado (borra de café) foi moldado em Laboratório (Laboratório de Pesquisa FINEP 2 Materiais - UFSCar/Campus Sorocaba) utilizando um molde de aço inoxidável, para compressão, adequado para formação de briquetes no formato cilíndrico, com diâmetro de $35 \mathrm{~mm}$ e $20 \mathrm{~mm}$ de altura.

O molde metálico foi acoplado a uma prensa hidráulica de laboratório e foi utilizada a força de moldagem de 10 toneladas para a compactação dos briquetes.

As moldagens preliminares dos briquetes somente com o pó de café foram realizadas nas seguintes quantidades: 10 briquetes com distribuição granulométrica da massa passante na malha com granulometria 20 
Mesh e retido na malha com granulometria 35 Mesh (Figura 1) e também 10 briquetes com o material passante na malha com granulometria 35 Mesh e retido na malha com granulometria 60 Mesh. (Figura 2).

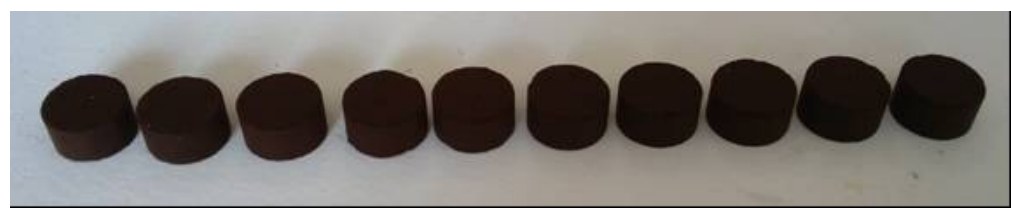

Figura 1: Briquetes moldados somente com pó de borra de café: material passante na malha com granulometria 20 Mesh e retido na malha com granulometria 35 Mesh .

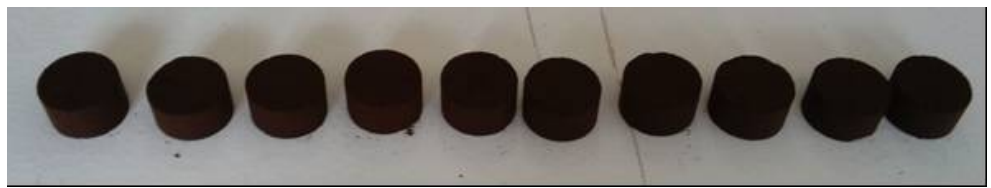

Figura 2: Briquetes moldados somente com pó de borra de café: material passante na malha com granulometria 35 Mesh e retido na malha com granulometria 60 Mesh.

As moldagens dos briquetes com a mistura da borra de café e serragem foram realizadas para o material com a seguinte distribuição granulométrica dos dois tipos de resíduos: passante na malha com granulometria 20 Mesh e retido na malha com granulometria 35 Mesh. As moldagens foram realizadas no mesmo molde de aço inoxidável e prensa hidráulica de laboratório nas mesmas condições experimentais dos briquetes moldados somente com pó de borra de café. As composições briquetadas (em \% em peso) foram as seguintes: $80 \%$ pó de borra de café $20 \%$ serragem de madeira; $70 \%$ pó de borra de café/30\% serragem de madeira; $60 \%$ pó de borra de café $/ 40 \%$ serragem de madeira; $50 \%$ pó de borra de café $/ 50 \%$ serragem de madeira e $40 \%$ pó de borra de café/ $60 \%$ serragem de madeira.

\subsection{Realização de ensaios de compressão diametral dos briquetes moldados}

Após a moldagem os briquetes foram condicionados em recipientes de vidro fechados (dessecadores sem sílica-gel) para manter a massa constante para a posterior realização dos ensaios de tração por compressão diametral (Figura 3), baseado na norma NBR 7222 (Associação Brasileira de Normas Técnicas, 1994) [26] com adaptações [ $\underline{27}, \underline{25}, \underline{28}]$.

Os ensaios foram realizados em equipamento da marca EMIC, modelo DL30000N localizado no Laboratório de Caracterização de Materiais (LECMat) do Campus de Sorocaba. Para os ensaios foi utilizada uma célula de carga de capacidade 500Kgf e velocidade de ensaio de $0,3 \mathrm{~mm} \mathrm{~s}^{-1}[25$, 27].

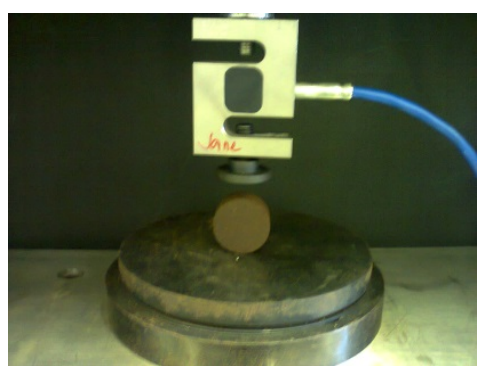

Figura 3: Briquete de pó de borra de café em 35 Mesh durante o ensaio por compressão diametral.

O ensaio por compressão diametral tem sido utilizado para comparar as propriedades mecânicas de resistência máxima à compressão e módulo de elasticidade [로, $\underline{30}, \underline{31}, \underline{28}]$.

\subsection{Determinação do teor de umidade}

O teor de umidade (Tu) de amostras de briquetes contendo borra de café foi medida em laboratório com auxílio de uma balança do tipo medidora de umidade, marca MARCONI modelo I-50. As análises foram realizadas em triplicata. 


\subsection{Determinação do poder calorífico superior (PCS)}

Foram retiradas amostras de 1,0 (um) grama dos briquetes formados por $100 \%$ café; $40 \%$ café/60\% de serragem e $50 \%$ café $/ 50 \%$ serragem para a determinação dos respectivos valores de poder calorífico superior, baseando-se na Norma NBR 8633, com o auxílio de equipamento do tipo bomba calorimétrica da marca IKAc200. As análises de determinação do poder calorífico superior (PCS) foram realizadas em triplicata.

\subsection{Análise do teor de cinzas e voláteis}

Amostras retiradas de alguns briquetes foram utilizadas para realização das análises dos teores de cinzas e de voláteis. Seguindo a metodologia da Norma NBR 8112, cada material após secagem por um período de 24 horas a $80^{\circ} \mathrm{C}$, foi pesado e, então, carbonizado na mufla a $650^{\circ} \mathrm{C}$ durante 3 horas. Depois deste período, as amostras foram deixadas esfriar e pesadas novamente. As análises dos teores de cinzas e voláteis de cada tipo de briquete foram feitas em triplicata.

O teor de voláteis (Tv) foi calculado utilizando a equação 1.

$T v=100 * \frac{(m 1-m 2)}{m 1}$

Equação 1 - Cálculo do teor de voláteis

onde: Tv - Teor de voláteis, \%

$\mathrm{m} 1$ - massa antes da queima, $\mathrm{g}$

m2 - massa após a queima, g

Para o cálculo do teor de cinzas (Tc) foi utilizada a equação 2.

$T c=100-T U-T v$

Equação 2 - Cálculo do Teor de cinzas

onde: Tc - Teor de cinzas, \%

TU - Teor de umidade, \%

Tv - Teor de voláteis, \%

\section{RESULTADOS E DISCUSSÕES}

\subsection{Ensaios de compressão diametral}

Analisando os dados dos ensaios de compressão diametral apresentados (Tabela 1) pode ser observado que para todas as composições de briquetes contendo serragem (em diversas porcentagens) ocorreram acréscimos nos valores das médias das propriedades de resistência máxima e módulo de elasticidade quando comparados aos valores destas propriedades dos briquetes moldados apenas com a borra de café (100\%).

Tabela 1: Valores médios de propriedades mecânicas para as composições de briquetes moldados e testados por compressão diametral.

\begin{tabular}{ccc}
\hline $\begin{array}{c}\text { Porcentagem de } \\
\text { serragem / borra de café }\end{array}$ & $\begin{array}{c}\text { Resistência Máxima (MPa) } \\
\text { e desvio padrão }\end{array}$ & $\begin{array}{c}\text { Módulo de Elasticidade (MPa) } \\
\text { e desvio padrão }\end{array}$ \\
\hline $0 \%$ / $100 \%$ & $0,09 \pm 0,02$ & $8,04 \pm 1,05$ \\
$60 \% / 40 \%$ & $0,27 \pm 0,04$ & $13,53 \pm 1,36$ \\
$50 \% / 50 \%$ & $0,26 \pm 0,04$ & $12,89 \pm 1,77$ \\
$40 \% / 60 \%$ & $0,25 \pm 0,04$ & $12,68 \pm 1,21$ \\
$30 \% / 70 \%$ & $0,22 \pm 0,05$ & $10,13 \pm 2,49$ \\
$20 \% / 80 \%$ & $0,20 \pm 0,02$ & $9,80 \pm 0,83$ \\
\hline
\end{tabular}


Considerando as composições dos briquetes contendo serragem e borra de café, os briquetes de composição no intervalo de $60 \%$ serragem de madeira/40 pó de borra de café até $40 \%$ de serragem/60\% pó de borra de café apresentaram valores próximos de módulo de elasticidade (Tabela 1) e de resistência máxima.

Na Tabela 1 pode ser considerado que os valores das propriedades mecânicas reduzem a partir da composição 30\% de serragem de madeira e $70 \%$ de pó de borra de café, ou seja, quanto menor a proporção de serragem de madeira utilizada menores são os valores de módulo de elasticidade e de resistência máxima dos briquetes. Assim, pode-se concluir que a serragem tem maior efeito para melhorar as propriedades mecânicas dos briquetes moldados devido, provavelmente, à estrutura de pequenas fibras presentes na serragem de madeira. Sabe-se que as fibras de serragem são materiais lignocelulósicos, ou seja, possuem em sua composição lignina, celulose, polioses (mistura de açúcares), além de extrativos e cinzas de sais minerais [34]. A lignina é uma macromolécula tridimensional amorfa, que apresenta diversos grupos aromáticos e alifáticos, além de inúmeros anéis fenilpropânicos substituídos A lignina é a principal responsável pela resistência mecânica das plantas ao dobramento e impacto, além da celulose [35]

Comparando as médias das resistências máximas por compressão diametral dos briquetes moldados no presente trabalho (Tabela 1) com um trabalho da literatura [25] neste foram encontrados valores de 0,82 MPa para os briquetes moldados com 100\% de serragem de madeira de eucalipto, com aquecimento a $120 \pm 5$ ${ }^{\circ} \mathrm{C}$ durante o processo de compactação dos briquetes. No entanto, neste trabalho aqui apresentado, o processo de compactação foi realizado à temperatura de $25 \pm 5^{\circ} \mathrm{C}$, sendo um fator que está relacionado à esta considerável diferença nos resultados.

Chrisostomo et al. [ㅌ] também observaram diferenças nos resultados de resistências máximas por compressão diametral de briquetes moldados em diferentes temperaturas, desde temperatura de aproximadamente $23{ }^{\circ} \mathrm{C}$ até temperatura de $180{ }^{\circ} \mathrm{C}$. No caso, conforme a temperatura de moldagem (compactação) foi aumentada, maiores foram os valores obtidos de resistências máximas por compressão diametral dos briquetes moldados. Conforme Chrisostomo et al. [ㅌ6], o aumento da resistência mecânica com o aumento da temperatura se deve à ação de aglutinantes naturais constituintes da biomassa de serragem, como a lignina, ativada pelo aquecimento, melhorando a adesão entre as partículas.

Em outro trabalho [29] briquetes moldados com resíduos de grãos de café carbonizados apresentaram valor médio de 0,39 MPa de resistência máxima por compressão diametral. Os valores de compressão diametral encontrados para as composições de briquetes moldados neste trabalho aqui apresentado estão mais próximos ao trabalho de Protásio et al. [28], provavelmente, devido ao tipo de resíduo ser proveniente também de café, porém, com a diferença de ter sido carbonizado em intervalo de temperatura de 50 até $450^{\circ} \mathrm{C}$, por cerca de 4,5 horas [28], antes de ser utilizado na compactação dos briquetes.

\subsection{Determinação do teor de umidade}

Na Tabela 2 estão apresentados os valores obtidos na determinação do teor de umidade (Tu) dos briquetes analisados. Pode ser observado que os valores encontrados de teor de umidade dos briquetes são similares.

Tabela 2: Valores médios de umidade (Tu) para algumas composições de briquetes moldados.

\begin{tabular}{cc}
\hline $\begin{array}{c}\text { Porcentagem de } \\
\text { serragem / borra de café }\end{array}$ & $\begin{array}{c}\text { Teor de umidade (\%) e } \\
\text { desvio padrão }\end{array}$ \\
\hline $0 \% / 100 \%$ & $9,40 \pm 0,30$ \\
$60 \% / 40 \%$ & $8,99 \pm 0,50$ \\
$50 \% / 50 \%$ & $9,05 \pm 0,16$ \\
\hline
\end{tabular}

Em trabalho da literatura [7] foram encontrados diversos valores de teores de umidade dependendo do resíduo, por exemplo, serragem com 11,3\% de umidade, cascas de grãos de café com 9,6 \% de umidade, cascas de arroz com 7,27\% de umidade, palha de trigo com 7,3\% de umidade, lascas de madeira de eucalipto com $11 \%$ de umidade, cascas de cacau com 8,8\% de umidade, entre vários outros resíduos. Portanto, os valores dos teores de umidade da Tabela 2 estão próximos a típicos valores de umidade de resíduos agroindustriais. Em outro trabalho da literatura [8] foram encontrados os valores de teores de umidade de 9,1\% para serragem de madeira; $11,4 \%$ de umidade para casca de arroz e 13,1\% de umidade para casca de grãos de café. 


\subsection{Determinação do poder calorífico superior (PCS)}

Na Tabela 3 estão os valores encontrados na determinação do poder calorífico superior (PCS) dos briquetes. O poder calorífico é um parâmetro para se avaliar a potencialidade energética de combustíveis de biomassa, sendo definido como a quantidade de energia liberada na combustão completa de uma unidade de massa do material combustível [25].

Tabela 3: Valores médios de poder calorífico superior (PCS) para algumas composições de briquetes moldados.

\begin{tabular}{cc}
\hline $\begin{array}{c}\text { Porcentagem de } \\
\text { serragem / borra de café }\end{array}$ & $\begin{array}{c}\text { PCS (MJ.kg-1) e } \\
\text { desvio padrão }\end{array}$ \\
\hline $0 \% / 100 \%$ & $20,08 \pm 0,55$ \\
$60 \% / 40 \%$ & $20,74 \pm 1,61$ \\
$50 \% / 50 \%$ & $20,31 \pm 1,37$ \\
\hline
\end{tabular}

De acordo com os valores de PCS da Tabela 3 pode ser observado que os resultados são semelhantes. Como os teores de umidade (Tabela 2) dos briquetes moldados foram próximos era esperado que os valores de PCS também fossem similares.

Em outros trabalhos da literatura [24, 32] resultados semelhantes foram obtidos, o que demonstra a correlação negativa existente entre o teor de umidade e o poder calorífico. A presença de umidade nos briquetes, geralmente, resulta em decréscimo do poder calorífico, já que parte da energia liberada é gasta na vaporização da água [33].

Na literatura [8] foram encontrados valores de potenciais caloríficos de alguns resíduos como, por exemplo, casca de arroz com 14,0 MJ/kg e casca de café com 18,4 MJ/kg. Em outro trabalho da literatura [10] foram encontrados valores de 16,78 a 18,96 MJ/kg para briquetes contendo serragem, e 15,77 a 18,19 MJ/kg para briquetes contendo bagaço de cana e glicerina.

Também foi encontrada literatura [24] que reporta o valor de PCS de 19312,76 kJ/kg (ou seja, 19,31 $\mathrm{MJ} / \mathrm{kg}$ ) para briquete contendo $100 \%$ de celulose proveniente de papéis diversos (papel ofício, revista, jornal entre outros).

Portanto, os valores de PCS obtidos neste trabalho (Tabela 3) estão de acordo com a literatura, e apresentam bons resultados relacionados ao poder calorífico, mesmo apresentando resultados de resistência mecânica inferiores (Tabela 1) ao da literatura, conforme comentado anteriormente. Assim, os resultados de PCS são favoráveis ao reaproveitamento da borra de café, devido ao potencial energético dos briquetes.

\subsection{Análise do teor de cinzas e voláteis}

Na Tabela 4 estão apresentados os valores obtidos na determinação do teor de voláteis (Tv) e do teor de cinzas (Tc) dos briquetes analisados.

Tabela 4: Valores médios dos teores de voláteis e de cinzas para algumas composições de briquetes moldados.

\begin{tabular}{ccc}
\hline $\begin{array}{c}\text { Porcentagem de } \\
\text { serragem / borra de café }\end{array}$ & $\begin{array}{c}\text { Teor de voláteis } \\
\mathbf{( \% )}\end{array}$ & $\begin{array}{c}\text { Teor de cinzas } \\
\mathbf{( \% )}\end{array}$ \\
\hline $0 \% / 100 \%$ & $84,64 \pm 2,35$ & $5,96 \pm 2,36$ \\
$60 \% / 40 \%$ & $85,84 \pm 1,03$ & $5,17 \pm 1,04$ \\
$50 \% / 50 \%$ & $85,57 \pm 1,30$ & $5,38 \pm 1,29$ \\
\hline
\end{tabular}


Os teores de cinzas e de voláteis são índices importantes para briquetes, pois estão relacionados ao potencial energético do material [24]. Quanto maior o teor de cinzas, maior a quantidade material inerte, ou seja, que não produz calor.

Os dados da Tabela 4 revelam que as propriedades analisadas apresentaram resultados próximos, o que revela a possibilidade de utilização das composições dos briquetes moldados e testados neste trabalho.

Na literatura [8] foram encontrados valores de 3,7\% de teor de cinzas para resíduos de cascas de grãos de café e $17 \%$ de teor de cinzas para cascas de arroz.

\section{CONCLUSÕES}

Através dos experimentos realizados pode-se afirmar a possibilidade de aplicação do pó da borra de café para briquetagem, sem necessidade de utilização de qualquer tipo de aglutinante (ou ligante) para a formação do briquete em prensa hidráulica e sem utilização de aquecimento.

Foi observado que todas as composições de briquetes contendo serragem (em diversas porcentagens) ocasionaram acréscimos nos valores das médias das propriedades de resistência máxima e módulo de elasticidade quando comparados aos valores destas propriedades dos briquetes moldados apenas com a borra de café (100\%). As diferentes composições de briquetes contendo serragem apresentaram valores próximos de resistência à compressão diametral.

De acordo com os valores do poder calorífico (PCS), as amostras contendo somente borra de café na composição apresentaram resultados próximos aos das amostras contendo borra de café e serragem.

Os resultados de PCS são favoráveis ao reaproveitamento da borra de café, devido ao potencial energético dos briquetes contendo este tipo de resíduo, que é comum em residências e em indústrias que fabricam café solúvel. Assim, o uso deste tipo de resíduo de café deve ser ainda mais estudado e ampliado nas indústrias que procuram utilizar energias renováveis em seus processos.

\section{AGRADECIMENTOS}

Os autores agradecem à CAPES e à FAPESP (projeto 06/60885-2).

\section{BIBLIOGRAFIA}

[1] HU, J., LEI, T. et al., "Economic, environmental and social assessment of briquette fuel from agricultural residues - A study on flat die briquetting using corn stalk”, Energy, v. 64, p.557-566, 2014.

[2] SILVA, C.A., Estudo Técnico-Econômico da Compactação de Resíduos Madeireiros para Fins Energéticos, Dissertação M.Sc. Faculdade de Engenharia Mecânica, UNICAMP, Campinas, SP, Brasil, 2007.

[3] BAHEL, E., MARROUCH, W., GAUDET, G. "The economics of oil, biofuel and food commodities”, Resource and Energy Economics, v. 35, pp. 599-617, 2013.

[4] DIAS, J. M. C. et al, Produção de briquetes e péletes a partir de resíduos agrícolas, agroindustriais $e$ florestais. Embrapa Agroenergia, Brasília, DF, 2012.

[5] HILOIDHARI, M., DAS, D., BARUAH, D.C. "Bioenergy potential from crop residue biomass in India”. Renewable and Sustainable Energy Reviews, v. 32, p.504-512, 2014.

[6] SIVAKUMAR, K., et al., "Perfomance Analysis on Briquetting Bio Mass with Different Size", Journal Procedia Engineering, v. 38, pp. 3824-3832, 2012.

[7] FERNÁNDEZ, R.G. et al., "Influence of physical properties of solid biomass fuels on the design and cost of ,storage installations”, Waste Management, v. 33, pp. 1151-1157, 2013.

[8] FELFLI, F.F. et al., "Biomass briquetting and its perspectives in Brazil”, Biomass and Bioenergy, v. 35, pp. 236-242, 2011.

[9] FILIPPETO, D., Briquetagem de resíduos vegetais: viabilidade técnicoeconômica e potencial de mercado. Dissertação M.Sc. Faculdade de Engenharia Mecânica, UNICAMP, Campinas, SP, Brasil, 2008.

[10] SAKKAMPANG, C., WONGWUTTANASATIAN, T. "Study of ration of energy consumption and gained energy during briquetting process for glycerin-biomass briquette fuel”, Fuel, v. 115, pp.186-189, 2014.

[11] CAIRES, R. R. Briquetagem de resíduos - Biomassa, UNICAMP, Campinas, SP, 2010.

[12] RAHMAN, A. et al., "Influence of size and shape on the strength of briquettes", Fuel Processing Technology, v. 90, pp. 1041-1046, 2009. 
[13] CABRAL, M. S., MORIS, V. A. S. "Reaproveitamento da borra de café como medida de minimização da geração de resíduos”, In: XXX Encontro Nacional de Engenharia de Produção, São Carlos, Brasil, 12 de outubro de 2010.

[14] MARTINS, A. C. G. Valorização da borra de café através da produção de biossurfactantes, Dissertação M.Sc. Universidade de Aveiro, Portugal, 2011.

[15] ADANS, M. R., DOUGAN, W., Waste products - coffee technology, 1 ed., Londres, Elsevier Applied Science, 1985.

[16] VIOTTO, L.A., Projeto e avaliação econômica de sistemas de secagem de borra de café, Dissertação M.Sc., UNICAMP, Campinas, SP, Brasil, 1991.

[17] PEREIRA, F. A. et al, "Propriedades Físico-químicas de briquetes aglutinados com Adesivo de silicato de sódio”, Floresta e Ambiente, v. 16, pp. 1-32, 2009.

[18] MURTHY, P. S. "Sustainable management of coffee industry by products and value addiction", $R e$ sources, Conservation and Recycling, pp. 45-58, 2012.

[19] BALLARIN, A. W., NOGUEIRA, M. "Determinação do módulo de elasticidade da madeira juvenil e adulta de Pinus taeda pó ultra-som”, Journal of the Brazilian Association of Agricultural Engineering, v. 25, n.1, pp. 19-28, 2005.

[20] DERCAN, B. et al. "Possibility of efficient utilization of wood waste as a renewable energy resource in Serbia”, Renewable and Sustainable Energy Reviews, v.16, pp. 1516-1527, 2012.

[21] AHIDUZZAMAN, M.; SADRUL ISLAM, A.K.M. "Development of biomass stove for heating up die barrel of rice husk briquette machine”, Procedia Engineering, v. 56, pp. 777-781, 2013.

[22] ROY, M. M.; CORSCADDEN, K. W. “An experimental study of combustion and emissions of biomass briquettes in a domestic wood stove”, Applied Energy, v.99, pp.206-212, 2012.

[23] ABIC, http://www.abic.com.br/publique/cgi/cgilua.exe/sys/start.htm?sid=61\#2304. Indicadores da Indústria de Café, 2012. Acessado em outubro de 2013.

[24] GONÇALVES, J.E. et al., "Energia de briquetes produzidos com rejeitos de resíduos sólidos urbanos e madeira de Eucalyptus grandis”, Revista Brasileira de Engenharia Agrícola e Ambiental, v.13, n.5, pp.657661, 2009.

[25] PROTÁSIO, T. P. et al., "Compactação de biomassa vegetal visando à produção de biocombustíveis sólidos”, Pesquisa Florestal Brasileira, v. 31, pp. 273-283, 2011.

[26] NBR 7222, "Determinação da resistência à tração por compressão diametral de corpos-de-prova cilíndricos: Método de ensaio”, ABNT. Associação Brasileira de Normas Técnicas. Rio de Janeiro, 1994.

[27] GARCIA, A., SPIM, J.A., SANTOS, C.A. Ensaios dos materiais. 1 ed. Rio de Janeiro, LTC Editora, 2000.

[28] PROTÁSIO, T. P. et al., “Torrefação e carbonização de briquetes de resíduos do processamento dos grãos de café”, Revista Brasileira de Engenharia Agrícola e Ambiental, v. 16, n.11, pp. 1252-1258, 2012.

[29] ALÓ, L.L., YAMAJI, F.M., KONISHI, P.A., et al., “Análise do Comportamento Higroscópico de Blendas de Biomassa”, In: $7^{\circ}$ Congresso Internacional de Bioenergia, São Paulo, Brasil, 1 novembro de 2012.

[30] FRANCO, A. J. Estudo e caracterização de composições de coque e fibras vegetais (bagaço de cana e madeira) para aplicação na produção de briquetes. Dissertação M.Sc. PPGCM/UFSCar, Universidade Federal de São Carlos/Campus Sorocaba, SP, Brasil, 2011.

[31] PAULA, L.E.R. et al. "Produção e avaliação de briquetes de resíduos lignocelulósicos”, Pesquisa Florestal Brasileira, v.31, n.66, pp.103-112, 2011.

[32] MENEZES, M. S. S. Poder calorífico e análise imediata da maravalha de Pinus (Pinus sp) e Araucária de reflorestamento como resíduos de madereira. Dissertação M.Sc. Universidade Estadual do Oeste do Paraná, Cascavel, Brasil, 2013.

[33] FERREIRA, J. C., FURTADO, T. S., NEVES, M. D., et al., "Influência do teor de umidade no poder calorífico em diferentes unidades e componentes de árvores de Pinus taeda”, In: $1^{\circ}$ Congresso Brasileiro sobre Florestas Energéticas, Belo Horizonte, Brasil, 02 de junho de 2009.

[34] CAMPAGNER, M.R. et al., "Filmes Poliméricos Baseados em Amido e Lignossulfonatos: Preparação, Propriedades e Avaliação da Biodegradação”, Polímeros, v. 24, n. 6, pp. 740-751, 2014.

[35] FENGEL, D., WEGENER, G. Wood Chemistry, Ultrastructure and Reactions, Walter de Grutyer, Berlin, 1989. 
[36] CHRISOSTOMO, W., YAMAJI, F. M., YAMAMOTO, H., et al., "Densificação da Serragem de Eucalyptus SP em Diferentes Temperaturas", In: Anais do $9^{\circ}$ Congresso Internacional de Bioenergia, São Paulo, Brasil, 01 a 03 de outubro de 2014. 